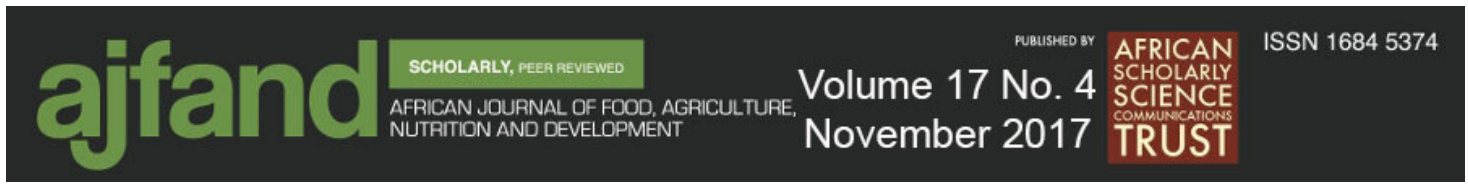

\title{
PARENTAL KNOWLEDGE, ATTITUDES AND PRACTICES REGARDING OVERWEIGHT AMONG PRESCHOOL CHILDREN IN RURAL ZIMBABWE
}

\section{Mushonga NGT ${ }^{1 *}$, Mujuru HA ${ }^{2}$, Nyanga LK $^{1}$, Nyagura $S^{1}$, Musaka $N^{1}$, and $R$ Dembah ${ }^{3}$}

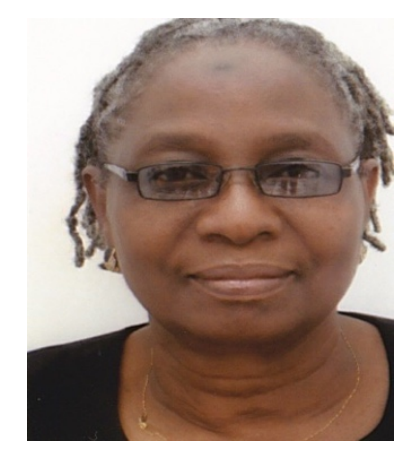

Nyasha Mushonga

*Corresponding author email: nyamushonga@gmail.com

${ }^{1}$ Institute of Food, Nutrition and Family Sciences, University of Zimbabwe. Box MP 167 Mt Pleasant, Harare, Zimbabwe

${ }^{2}$ Department of Pediatrics and Child Health, University of Zimbabwe College of Health Sciences. PO Box A178. Avondale, Harare, Zimbabwe

${ }^{3}$ Department of Statistics, University of Zimbabwe Box MP 167 Mt Pleasant, Harare, Zimbabwe 


\section{ABSTRACT}

Parents have significant influence in the development of children's eating behaviour and food choices. Their knowledge and attitudes towards nutritional status play an important part in childhood growth, as parents become role models in shaping children's eating habits. The aim of this study was to assess parental knowledge and attitudes towards childhood nutritional status and evaluate the relationship between eating habits, knowledge and attitudes of parents. A cross-sectional study was conducted in five districts of Mashonaland East Province of Zimbabwe. A total of 241 parents of preschool children were selected using multi-stage sampling technique. Questionnaires were administered to parents who gathered at the selected primary schools in the Districts. Data was analysed using SPSS version 16 (2007) and MS Excel. Spearman's Coefficient Correlation at a $95 \%$ significance level was used to measure the strength of linear association between knowledge and attitude score as well as education level, gender and food consumption scores. Results showed that parents in Mashonaland East Province of Zimbabwe had a poor to moderate nutrition knowledge and understanding of the causes of overweight among preschool children. There was a significant association between education level of parents and nutrition knowledge scores attained $(\mathrm{p}=0.028)$. Food consumption score was significantly associated with knowledge score $(p=0.008)$. Furthermore, $0.4 \%$ of the parents with good nutrition knowledge had acceptable food consumption scores. This study showed that most parents $(83.4 \%)$ were knowledgeable about the concept of a balanced diet. However, this was not translated into practice as $72 \%$ of the parents had poor to borderline food consumption score. Nutrition gaps identified in this study included failure by parents to link skipping breakfast to overweight among children and that exclusive breast feeding contributes to weight reduction. Parents did not acknowledge that eating at least 5 servings of fruits and vegetables is beneficial in maintaining healthy body weight and that being overweight is a risk factor for type 2 diabetes mellitus. The results further demonstrated that parents in the province require additional nutrition knowledge to help curb overweight among preschool children by giving appropriate nutritious foods.

Key words: Parents, children, knowledge, attitude, food consumption score, weight, nutritional status 


\section{INTRODUCTION}

Globally, the number of overweight children under the age of five years has been estimated to be over 43 million, and is expected to reach 60 million in 2020 [1]. Estimates in Africa showed that the number has doubled to 10.6 million from 5.4 million in 1990 [2]. De Onis et al. [3] reported that globally, overweight prevalence among preschool children increased from $4.2 \%$ to $6.7 \%$ in 2010 and the trend is expected to increase to $9.1 \%$ by 2020 . In Africa, the estimated prevalence of childhood overweight was $8.5 \%$ in 2010 and is expected to increase to $12.7 \%$ in 2020 [3]. Zimbabwe observed a $3.1 \%$ overweight prevalence in 2010 and in 2011 it was 6\% [4, 5]. A study conducted by Mushonga et al. [6] showed an overweight prevalence of $7.2 \%$ among preschool children aged 36 to 60 months in Harare suburbs, which is slightly higher than previously reported in Zimbabwe. Overweight is a major risk factor for non-communicable diseases (NCDs) such as cardiovascular disease, type 2 diabetes and many cancers (including colorectal, kidney and esophageal cancers) [7, 8]. Scientific evidence has shown that overweight children are more likely to remain overweight as adolescents and become overweight or obese adults [9]. However, most parents see their children become overweight without taking action believing that the child will outgrow the weight, contrary to scientific knowledge [9].

The causes of overweight are diverse. Research has shown that parents play a very important role in the development of children's eating behaviour, energy intake and food preferences [10]. Maternal and child nutrition are among the key factors that determine the outcome of human development and significantly influence the quality of life in later years [11]. According to Beegum [12], parents are critical to the long- term adoption of various health practices and nutrition knowledge by children. The environment, genetics, ethnicity and socio-economic factors contribute to overweight among children. Therefore, parents need to understand the benefits of having correct nutrition knowledge and positive attitude towards healthy eating behaviours that promote good nutrition in children. In the African culture, being overweight is viewed as being healthy and wealthy; some parents have the perception that being overweight signifies wealth and prosperity $[13,14,15]$.

Childhood overweight is likely to continue into adulthood giving health and economic burdens to the individual, family and nation at large. Parental nutrition knowledge forms the basic strategy for preventing and managing childhood overweight. Scientific information on parental knowledge and attitudes towards nutritional status of children aged 36-60 months in Zimbabwe is scanty. This study sought to establish the level of parental nutrition knowledge and attitudes towards overweight among preschool children and determine the eating patterns among parents of preschool children in Mashonaland East Province, Zimbabwe. The specific objectives were to determine the parental nutritional knowledge level, establish an association between parental education level and nutrition knowledge, and to compare the food consumption and nutrition knowledge. 


\section{MATERIALS AND METHODS}

\section{Study Design}

A descriptive cross-sectional study was carried out between April and July 2014 in the Mashonaland East Province of Zimbabwe. A multi-stage sampling process was used to determine the research sites for data collection. Mashonaland East province of Zimbabwe with nine districts was conveniently chosen out of 10 provinces, and out of the nine districts five were randomly selected using MS Excel. The selected Districts were Goromonzi, Marondera, Murehwa, Mudzi and Chikomba.

A list of all preschools in each of the selected districts was obtained from the District Education Offices. A total of 25 preschools, five from each District, were randomly selected out of 457 preschools in the five districts by picking the names of preschools from a hat. At each of the five preschools in a district, children in the age group 36-60 months were given letters requesting their parents to attend a questionnaire interview at the school. Out of the 350 children whose parents received invitation letters, 241 parents consented in writing to participate in the study. Parents assembled at the school and were given questionnaires to answer after a brief explanation of the purpose of the exercise.

\section{Data collection techniques}

A structured questionnaire was used to collect data. The instrument was developed from Food Frequency Questionnaire (FFQ) by Gibson [16] and Food Guide Pyramid [17]. Two trained nutritionists administered the questionnaires, which had three sections. The first was on demographic data that included age, sex, education, income, employment and marital status. The second section had statements grouped as general, food and exercise and based on a five-point Likert scale from strongly disagree to strongly agree $[18,19]$. Knowledge and attitude (KA) scores were added to compute a total score [20]. The highest possible score was 21 and zero was the lowest. The scores were divided into three categories: $<10=$ poor; $10-15=$ moderate and $16-21=\operatorname{good}[20]$.

The third section was a Food Frequency Questionnaire (FFQ) administered to parents [16]. The questionnaire was administered in Shona, the vernacular language used in that part of Zimbabwe. The instrument was pretested before data collection. This was conducted at a preschool in Harare in a district where the study was not going to be conducted. A total of 20 randomly selected parents participated in the pretest. The purpose was to validate the questionnaire for clarity of questions and language used. The questionnaire was adjusted according to comments that were raised. The data collected was not analysed.

\section{Data analysis}

Data was analysed using SPSS version 16, (2007) and MS Excel. Spearman's Coefficient of Correlation at $95 \%$ significance level was used to measure the strength of linear association between KA scores and education level, gender and food consumption scores. Food consumption scores were used to determine adequacy of diet for both children and parents of preschool children in the study based on World Food Programme (WFP)/Food and Agriculture Organization (FAO) calculations [21]. 


\section{Ethical Considerations}

This study was approved by the Medical Research Council of Zimbabwe. Permission was also sought and granted by the Ministry of Health and Child Care and Ministry of Primary and Secondary Education. Informed consent was sought from participating parents. No names of parents were asked for and addresses used were for the preschool, therefore, ensuring anonymity and confidentiality.

\section{RESULTS}

The study population was composed of $25(10.4 \%)$ males and $216(89.6 \%)$ females with a mean age of $34.5( \pm 11.1)$ years for both males and females and $71 \%$ were married. In rural areas, females manage most households while men are at work in urban areas or self-employed away from home. The majority (91.3\%) of the respondents had a family monthly income below US $\$ 500.00$. The poverty datum line for Zimbabwe is US $\$ 494.16$ [22]. Unemployment rate for both males and females in this survey group was $41.5 \%$, and self- employment ranked second at $35.3 \%$.

There was a significant association between parental nutrition knowledge and food consumption scores $(\mathrm{p}=0.008)$ as shown in Table 1 . A small proportion $(0.4 \%)$ of parents with poor to borderline food consumption scores had good nutrition knowledge scores, while in the same food consumption category $45.7 \%$ had moderate nutrition knowledge score. Furthermore, $0.4 \%$ of the parents with good nutrition knowledge had acceptable food consumption score.

Table 2 shows a significant association between nutrition knowledge score and consumption of fruits and vegetables $(\mathrm{p}=0.046)$. There were more participants $(35.1 \%)$ in the poor knowledge category who never consumed fruits and vegetables in comparison to those in the moderate knowledge category $(25.9 \%)$ who never consumed these foods. Inversely, there were less $(9.1 \%)$ in the poor knowledge category who consumed fruits and vegetables on a daily basis, while $18.5 \%$ in the moderate knowledge category included fruits and vegetables in their daily diet. Table 3 shows that almost all parents $(99.6 \%)$ consumed cereals on a daily basis. About half of the households $(47.9 \%)$ consumed vegetables daily. There was a high consumption of sugar and oil with almost all households (99.2\%) taking these on a daily basis as illustrated in Table 3 . The majority of the participants $(82.2 \%)$ disagreed that skipping breakfast could contribute to a child being overweight (Table 4). There was no significant relationship between level of education and breakfast consumption. Table 4 illustrates that $56.4 \%$ of the participants disagreed that eating five servings of fruits and vegetables or more daily contributes to weight reduction among preschool children.

The majority of parents $(62.2 \%)$ indicated that exclusive breastfeeding had no effect on weight reduction and $54.4 \%$ of the participants did not know that rewarding children with food for good behaviour is likely to contribute towards overweight (Table 4).

More than sixty percent of the parents $(63.5 \%)$ disagreed that sleeping late and waking up late has an effect on a child being overweight. Eighty-eight percent of the participants were aware that physical activity was a necessary component of good health and $10 \%$ 
did not agree with the statement. Approximately $70 \%$ of the participants agreed that overweight is a risk factor for heart disease whilst less than $50 \%$ did not consider overweight to be a risk factor for type 2 diabetes mellitus.

Most parents $(83.4 \%)$ were able to correctly respond to the statement "A balanced diet has all food groups", though the majority $(72 \%)$ had poor to borderline food consumption score as illustrated in Table 2.

On attitude statements, $71 \%$ of the parents disagreed that being overweight is a sign of being healthy as shown in Table 4 . However, $53 \%$ of the parents believed that most of the overweight observed in children aged 36-60 months is due to genetic make-up. Of the 241 participants, $162(67.2 \%)$ did not think that food advertising has an impact on overweight in children.

\section{DISCUSSION}

\section{Parental nutrition knowledge in relation to educational level}

The present study showed that parents in Mashonaland East Province, Zimbabwe, have a moderate to poor nutrition knowledge on causes and effects of overweight among preschool children. The results of this study demonstrated a significant association between education level of parents and nutrition knowledge scores that they attained ( $\mathrm{p}$ $=0.028$ ) at $5 \%$ significance level. Correct nutrition knowledge is related to positive health status [23]. The results demonstrated that parents in the province require further nutritional knowledge that would contribute to the reduction of both under and overweight among preschool children. Parents with secondary school education had moderate nutrition knowledge score compared to those who had no education or just primary level education even though some failed to correctly respond to pertinent statements. These results are similar to those found by El-Nmer et al. [23] which showed a significant relationship between parental education level and nutrition knowledge score. According to Variyam et al. [24] and Neuhouser et al. [25], higher school education level is related to healthy eating habits and lowers the prevalence of overweight in children. A study by Akbari et al. [26] showed that when parents are educated on nutrition and health issues they become knowledgeable on the causes and effects of overweight in their children, then they are likely to take action. United Nations Children's Fund (UNICEF) nutrition conceptual framework showed that inadequate school education is likely to contribute to inadequate dietary intake, poor child caring practices and also lead to presence of disease [27]. Parental education level may have an influence on a child's risk for over-weight, for example, parents with less knowledge about the role of nutrition and physical activity may not see the importance of both aspects [23]. Poor nutrition and physical inactivity have been sighted as causes of overweight in both children and adults [23]. Overweight is one of the known risk factors for noncommunicable diseases. Hence, nutrition knowledge of parents in this study needs to be increased so as to improve their children's eating habits and reduce consequences of overweight. The results of this study emphasize the concept that nutrition education is instrumental in improving eating habits. 
Parental nutrition knowledge in relation to gender

There was no significant relationship between parental knowledge scores and gender in this study $(\mathrm{p}=0.243)$. However, the results demonstrated that females $(68.4 \%)$ had moderate to good nutrition knowledge while males $(42.3 \%)$ had moderate nutrition knowledge scores. It is common practice that female parents take children to health centres for various services where health and nutrition education is taught building up their knowledge base. Gebremedhin found similar results showing that gender was not a factor in determining nutrition knowledge levels [28].

\section{Nutrition knowledge in relation to food consumption}

An increase in nutrition knowledge would lead a parent to give a child balanced nutritious food because they would understand which nutrients are of importance to the health of the child. The correlation between food consumption and knowledge score was found to be significant $(\mathrm{p}=0.008)$ in this study. Parental knowledge of nutrition in this study is low and seems to significantly be affected by dietary intake. Increased nutrition knowledge is likely to influence reduction of overweight among preschool children [29]. The food consumption scores of parents in this study are comparable to those observed in Zimbabwe Demographic and Health Survey (ZDHS) and Zimbabwe Multiple Indicator Cluster Survey (MICS), which documented the minimum acceptable diet as $17.3 \%$ and $11 \%$, respectively $[5,30]$. Dietary intake in Zimbabwe has not changed much; possibly due to the prevailing harsh economic environment. The difference between data sets could be dependent on food seasonality, time of data collection and sampling methods. Healthy eating habits are closely associated with proper cognitive development. The fact that parental nutrition knowledge ranges from poor to moderate scores is likely to be associated with poor food consumption and failure to put knowledge gained into practice. According to Jahns and Kranz, people in most parts of the world are now consuming adequate calories but from unhealthy foods unlike in the past where people consumed wholesome foods [31].

\section{Identified nutrition gaps}

This study was able to identify pertinent knowledge gaps that are closely linked to overweight among children as illustrated in Table 4. Parents in Mashonaland East Province were unable to link type 2 diabetes mellitus to overweight, while they had knowledge that heart disease is associated with being overweight. They also displayed lack of knowledge on the advantages of exclusive breastfeeding, one of which is contributing to weight control. According to Beeghum [12], Moreno et al. [32] and Yan [33] exclusive breastfeeding reduces the risk of overweight in infants and young children. Gaining this knowledge is likely to impact positively on the nutritional status of children and increases the rates of exclusive breastfeeding. Another knowledge gap that was identified in this study is skipping breakfast, which might contribute to overweight among children and adolescents. Over $80 \%$ of the parents disagreed with the statement and yet most of them had secondary education and were expected to have better understanding of nutrition knowledge [29]. There was no significant association between skipping breakfast and nutrition knowledge score. Parents should, however, be encouraged to give children breakfast, as skipping the first meal may lead to consumption by children of non-nutritious foods such as sweets, potato crisps, biscuits, sugar added drinks among other foods which is likely to cause overweight among the 36-60 months 
age group [34]. In this study, less than $50 \%$ of the parents expressed knowledge on the importance of including fruits and vegetables in their diet. Eating at least 5 servings of fruits and vegetables daily is strongly recommended, more so in managing weight as these products have low energy value and high fibre, which helps in satiety value [35]. Micronutrients found in fruits and vegetables are essential in promoting healthy nutrition. Besides, fruits and vegetables help in building strong immunity among children [36]. This study showed that more parents who had poor nutrition knowledge score never consumed fruits and vegetables, while those who had moderate knowledge score consumed them daily. Many people fail to consume fruits and vegetables partly because they are expensive or that they are found seasonally [37]. However, in Zimbabwe indigenous fruits and vegetables are still found in most parts of the country and almost all year round, but consumption has reduced tremendously due to adoption of Western type of diet which is a trend found in most developing countries [31]. Other nutritional and attitude knowledge gaps identified in this study were use of food as a reward for good behaviour, which encourages children to eat in the absence of hunger. Studies have shown that sleeping late and waking up late of a child is likely to contribute towards overweight $[38,39]$. In addition, it has been reported that lack of sleep increases the hunger hormone-ghrelin and decreases satiety hormone-leptin [40]. Children tend to sleep late watching television or playing sedentary games at the same time eating snacks and drinking sugar sweetened beverages [31]. Most parents (53\%) agreed that overweight being experienced is due to genetics and, therefore, do not take action to prevent or manage it among their children in the belief that it will disappear as the child grows. Scientific research, however, does not attribute the entire overweight being observed to genetics but to excess energy intake and less energy expenditure [9].

Parents were knowledgeable on balanced diet as over $80 \%$ of them had correct responses implying that they know what constitutes proper eating habits. However, this study has shown that knowledge was not translated into practice as the diets were not diversified, leading to poor and borderline food consumption score levels. Data on food consumption score show a significant disparity between knowledge of balanced diet and eating habits. The diet consisted of cereals and vegetables, which were likely to be consumed in small quantities. Sugar and oil was consumed almost daily by $99 \%$ of households. This shows poor food diversity and supports low food consumption scores that have been identified in this study. The Department of Nutrition, in the Ministry of Health and Child Care of Zimbabwe has advocated the use of the 4 Star Diet to help communities come up with a balanced diet [41]. Lack of uptake of the 4 Star Diet concept could be due to poor access, availability and affordability of food commodities as well as inadequate nutrition knowledge. As a result, foods that are frequently consumed on a daily basis are sugar and oil that contribute more calories with low nutrients and the energy consumed is not likely to be easily expended, thus leading to overweight.

This study has shown that parents in Mashonaland East Province need to improve their nutrition knowledge levels as this can assist in improving the nutritional status of their children. Even though the prevalence of overweight is not yet as high as what is reported in the Western world, parental nutrition knowledge and positive attitudes are important in overweight reduction and prevention among children. Parents may take time to act on overweight in the belief that children will outgrow the weight. Preschool age is an 
appropriate age group to influence good eating behaviour as children are able to decide on which foods to eat and are even willing to try new foods without much resistance; therefore, parental nutrition knowledge will help to instill appropriate eating patterns [12]. Research has established that an improvement in nutrition knowledge is an important tool to stimulate positive dietary behaviour that will promote healthy weight for generations to come [42]. Therefore, parents should be empowered with practical and implementable nutrition knowledge as they have great influence on children's dietary habits and nutritional status.

\section{CONCLUSION}

The study has shown that very few parents $(0.8 \%)$ in Mashonaland East Province had good nutrition knowledge, while the majority had low level of nutrition knowledge. Parental attitudes towards overweight were weak. This study showed a significant association between nutrition knowledge score and consumption of fruits and vegetables. Gaps in nutrition knowledge and attitude were identified particularly on causes of overweight and its prevention.

In order to address the challenge of overweight, parents can be encouraged to form community clubs where nutrition and health education is taught and demonstrated. Intensive nutrition education should be given to parents/caregivers whenever they visit clinics and school functions to empower them in making informed choices on diet for their children. Further studies are needed to substantiate the role of nutrition knowledge on the development of overweight in low income countries. One such study could involve investigating association of maternal and child weight in relation to eating habits.

\section{Limitations of Study}

Not many studies on this subject within the region were found. Comparisons were limited as most studies made reference to developed countries such as USA and Europe. The sample size (241) was not large enough to generalize the results. 


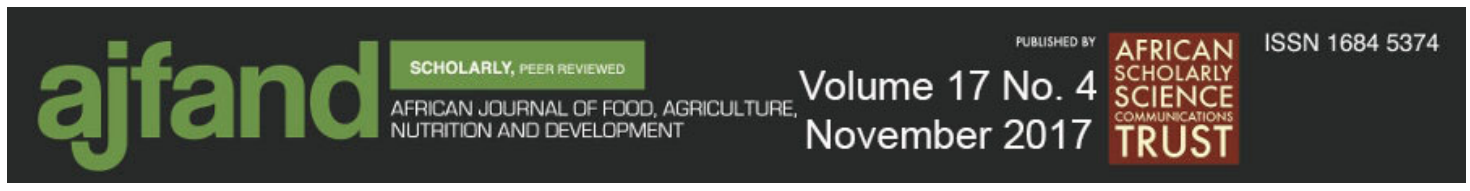

Table 1: Relationship between parental nutrition knowledge and food consumption scores

\begin{tabular}{|c|c|c|c|c|c|}
\hline & \multicolumn{3}{|c|}{ Food consumption score } & \multirow{2}{*}{$\begin{array}{c}\text { Total } \\
(\%)\end{array}$} & \multirow[t]{2}{*}{ p-value } \\
\hline $\begin{array}{l}\text { Knowledge score } \\
\text { categories }\end{array}$ & $\begin{array}{c}\text { Poor } \\
(\%)\end{array}$ & $\begin{array}{c}\text { Borderline } \\
\text { (\%) }\end{array}$ & $\begin{array}{c}\text { Acceptable } \\
(\%)\end{array}$ & & \\
\hline Poor & $14(5.8)$ & $49(20.3)$ & $14(5.8)$ & $77(32.0)$ & \\
\hline Moderate & $17(7.1)$ & $93(38.6)$ & $52(21.6)$ & $162(67.2)$ & 0.008 \\
\hline Good & 0 & $1(0.4)$ & $10(0.4)$ & $2(0.8)$ & \\
\hline Total & $31(12.8)$ & $143(59.3)$ & $67(27.8)$ & $241(100)$ & \\
\hline
\end{tabular}

Cut-off points for food consumption score

Poor $=0-28$ points; Borderline $=28.5-42$ points; Acceptable $=>42$

Nutrition Knowledge scores

Poor $=<10 ;$ Moderate $=10-15 ;$ Good $=16-21$

Table 2: Association between fruits and vegetables consumption and nutrition knowledge score of parents of pre-school children in Mashonaland East Province

\begin{tabular}{|c|c|c|c|c|c|c|c|c|c|}
\hline & \multicolumn{7}{|c|}{ Fruit and vegetable consumption } & \multirow[b]{2}{*}{ Total } & \multirow[b]{2}{*}{ P-value } \\
\hline $\begin{array}{l}\text { Knowledge } \\
\text { score categories }\end{array}$ & Never & $\begin{array}{c}1-3 / \\
\text { Month }\end{array}$ & $\begin{array}{c}2-4 / \\
\text { Week }\end{array}$ & $\begin{array}{c}1 / \\
\text { week }\end{array}$ & $\begin{array}{l}2-3 / \\
\text { day }\end{array}$ & 1/day & $\begin{array}{c}\text { missing } \\
\text { data }\end{array}$ & & \\
\hline Poor & 27 & 26 & 7 & 3 & 1 & 7 & 6 & 77 & \multirow{4}{*}{$0.046^{*}$} \\
\hline Moderate & 42 & 43 & 12 & 19 & 8 & 30 & 8 & 162 & \\
\hline Good & 0 & 1 & 1 & 0 & 0 & 0 & 0 & 2 & \\
\hline Total & 69 & 70 & 20 & 22 & 9 & 37 & 14 & 241 & \\
\hline
\end{tabular}




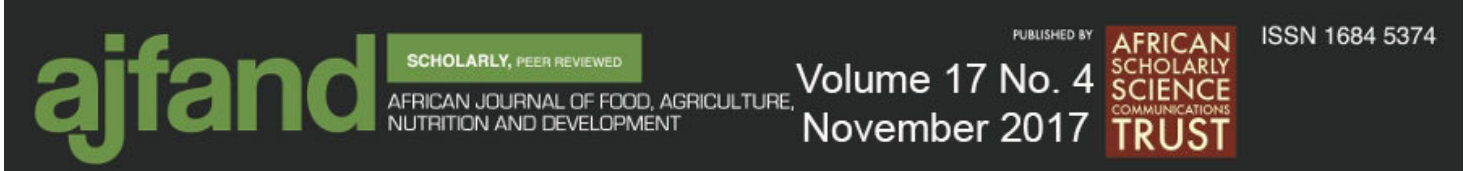

Table 3: Parental frequency of consumption of different food groups over a 7-day period (Mashonaland East Province)

\begin{tabular}{|l|c|c|c|c|c|c|c|c|}
\hline \multirow{2}{*}{$\begin{array}{l}\text { Food } \\
\text { groups }\end{array}$} & \multicolumn{6}{|c|}{ Parents consuming particular food groups (\%) and no. of days per week: N=241 } \\
\cline { 2 - 9 } & $\mathbf{0}($ never) & $\mathbf{1}$ & $\mathbf{2}$ & $\mathbf{3}$ & $\mathbf{4}$ & $\mathbf{5}$ & $\mathbf{6}$ & $\mathbf{7}(\mathrm{daily})$ \\
\hline Pulses & $81(33.8 \%)$ & $54(22.5 \%)$ & $49(20.4 \%)$ & $9(3.6 \%)$ & 0 & 0 & 0 & $42(17.5 \%)$ \\
\hline Cereals & $1(0.4 \%)$ & 0 & 0 & 0 & 0 & 0 & 0 & $240(99.6 \%)$ \\
\hline Vegetables & $43(17.9 \%)$ & $18(7.5 \%)$ & $46(19.2 \%)$ & $18(7.5 \%)$ & 0 & 0 & 0 & $115(47.9 \%)$ \\
\hline Fruit & $179(74.3 \%)$ & $43(17.8 \%)$ & $17(7.1 \%)$ & $2(0.8 \%)$ & 0 & 0 & 0 & 0 \\
\hline $\begin{array}{l}\text { Meat and } \\
\text { fish }\end{array}$ & $47(19.5 \%)$ & $53(22 \%)$ & $111(46.1 \%)$ & $23(9.5 \%)$ & $7(2.9 \%)$ & 0 & 0 & 0 \\
\hline Milk & $196(81.3 \%)$ & $39(16.2 \%)$ & $5(2.1 \%)$ & 0 & 0 & 0 & 0 & $1(0.4 \%)$ \\
\hline Sugar & $2(0.8 \%)$ & 0 & 0 & 0 & 0 & 0 & 0 & $239(99.2 \%)$ \\
\hline Oil & $2(0.8 \%)$ & 0 & 0 & 0 & 0 & 0 & 0 & $239(99.2 \%)$ \\
& & & & & & & & \\
\hline
\end{tabular}




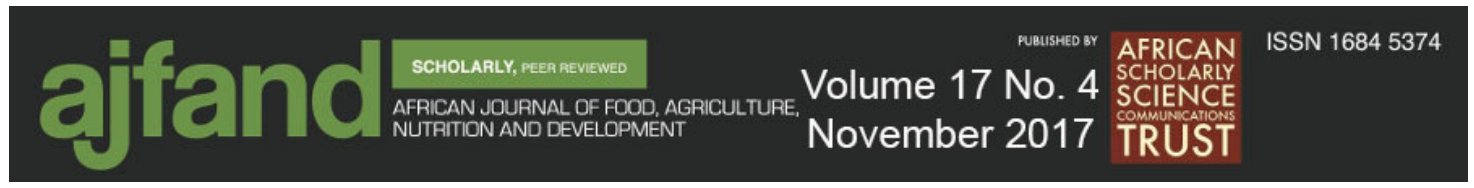

Table 4: Mashonaland East Province: Parental nutrition knowledge and attitude responses to nutrition statements

\begin{tabular}{|l|c|c|}
\hline Statement & Agree \% & Disagree \% \\
\hline Heart disease is a risk factor for overweight & 69.3 & $30.7^{*}$ \\
\hline Diabetes is a result of being overweight & 48.1 & $51.9^{*}$ \\
\hline Exclusive breastfeeding reduces overweight & 37.8 & $62.2^{*}$ \\
\hline Skipping breakfast contributes to overweight among children & 17.8 & $82.2^{*}$ \\
\hline Eating more fruits and vegetables reduces weight & & \\
\hline Balanced diet has all food groups & 43.6 & $56.4^{*}$ \\
\hline Using food as reward for good behaviour contributes to overweight & 45.6 & $54.4^{*}$ \\
\hline $\begin{array}{l}\text { Food advertising has great influence in preschool children being } \\
\text { overweight }\end{array}$ & & \\
\hline Sleeping late and waking up late contributes to overweight & & \\
\hline Anysical activity is a necessary component to good health & & \\
\hline & & \\
\hline
\end{tabular}

*Indicate nutrition and attitude knowledge gaps that have been identified in the study 


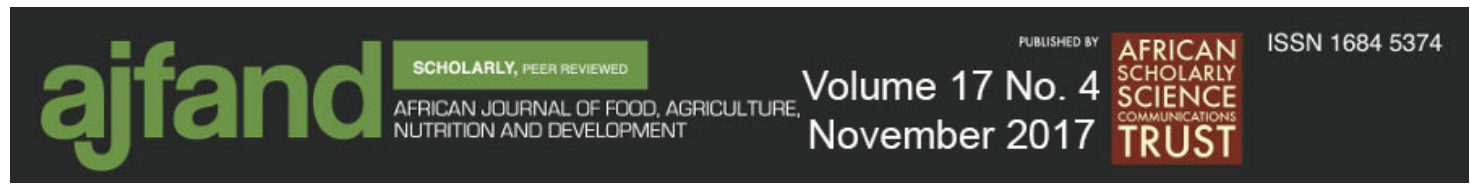

\section{REFERENCES}

1. Gebremedhin S Prevalence and differentials of overweight and obesity in preschool children in Sub-Saharan Africa. BJM Open 2015; 5: e009005. doi:10.1136/bjmopen-2015-009005.

2. WHO. 2016, Fact Sheet. Geneva, Switzerland.

3. De Onis M, Blossner $\mathbf{M}$ and $\mathbf{E}$ Borghi Global Prevalence and Trends of overweight and obesity among preschool children. Am J Nutr 2010; 92 (5):12571264.

4. Zimbabwe National Nutrition Survey. Food and Nutrition Council and Ministry of Health and Child Welfare; 2010.

5. Zimbabwe National Statistics Agency (ZIMSTAT) and ICF International). Zimbabwe Demographic and Health Survey 2010-11, Calverton, Maryland: ZIMSTAT and ICF International Inc.; 2012.

6. Mushonga NG, Mujuru HA, Nyanga LK, Nyagura S, Chikowore RM and L Siziba Factors associated with overweight/obesity among preschool children aged 3-5 years in Harare, Zimbabwe: A cross-sectional study. JASSA 2015; 20 (2).

7. Ezzati M, Lopez AD, Rogers A and CJL Murray (eds). Comparative quantification of health risks. Global and regional burden of disease attributable to selected major risk factors. 2004; Geneva, World Health Organization.

8. World Cancer Research Fund/ American Institute for Cancer Research. Food, Nutrition, and the Prevention of Cancer: a Global Perspective. Washington DC: AICR, 2007

9. $\quad$ Rome ES Obesity Prevention and Treatment, Pediatr Rev. 2011; 32:363-373.

10. Birch LL, Fisher JO, Castro CN, Grimm-Thomas K, Sawyer R and SL Johnson Confirmatory factor analysis of the Child Feeding Questionnaire: a measure of parental attitudes, beliefs and practices about child feeding and obesity proneness. Appetite. 2001; 36:201-10.

11. Ayieko MA and JL Anyango Evaluation of Nutrition Knowledge and Perception of Good Food among Nursery School Pupils in Kisumu MunicipalityKenya. Adv J Food Science \& Technology. 2011; (3): 165-172.

12. Beegum MR Speaking of Child Care and Nutrition. 1999; New Dawn Press, INC. UK. USA. India. 
13. Baughcum AE, Chamberlin LA, Deeks CM, Powers SW and RC Whitaker Maternal perception of overweight preschool children. Pediatr 2000; 106:13806.

14. Kumanyika S, Wilson JF and A Guilford-Davenport Weight-related attitudes and behaviors of black women. J. Am Diet Assoc 1993; 93: 416-22.

15. Walker ARP, Adam F and BF Walker World Pandemic of Obesity: the situation in Southern African Populations. Public Health 2001; 115: 368-372. Doi:10.1038/sj.ph.1900790.

16. Gibson RS Principles of Nutritional Assessment. 2005. 2 ${ }^{\text {nd }}$ Edition. Oxford University Press, New York, USA.

17. USDA Food Guide Pyramid.2012. http://www.cnpp.usda.gov/FGP Accessed on 13 April 2016.

18. MacKinney JD "Preschool Teachers' Perceptions of Obesity at Ages 3-5 Years" PCOM Psychology Dissertations. 2010; 88.

19. Ministry of Health, Zimbabwe. Assessment of Health Worker Knowledge, Attitudes and Beliefs towards Breastfeeding, 2008. Ministry of Health and Child Welfare, Zimbabwe June 2012.

20. Rezaei OM, Moodi M and N Moazam Analyzing the level of knowledge and attitude of mothers referring the urban health centres of Birjand about nutritional behaviours. $J$ Educ Health Promotion 2014; 3:37 doi:10.4103/22779531.131915.

21. WFP/FAO. Interagency Workshop Report WFP-FAO. Measures of Food Consumption-Harmonizing Methodologies. Rome, April 2008.

22. ZIMSTAT Poverty Datum line 2015.

23. El-Nmer F, Salama AA and D Elhawary Nutritional knowledge, attitude and practice of parents and its impact on growth of their children. Menoufia Med J. 2014; 27:612-6.

24. Variyam JN, Blaylock J, Lin B, Ralston $\mathbf{K}$ and D Smallwood Mother's nutritional knowledge and children's dietary intakes. Am J. Agric Econom 1999; 81:373-84.

25. Neuhouser ML, Kristal AR and RE Patterson Use of food nutrition labels is associated with lower fat intake. J Am Diet Assoc. 1999; 99(1): 45-53.

26. Akbari N, Forozandeh $\mathbf{N}$ and $\mathbf{M}$ Delaram The effect of education on parental perception of obesity in their 6-12 year old children. Int J. Endocrinol Metab. 2007; 5 (2): 76-81. 


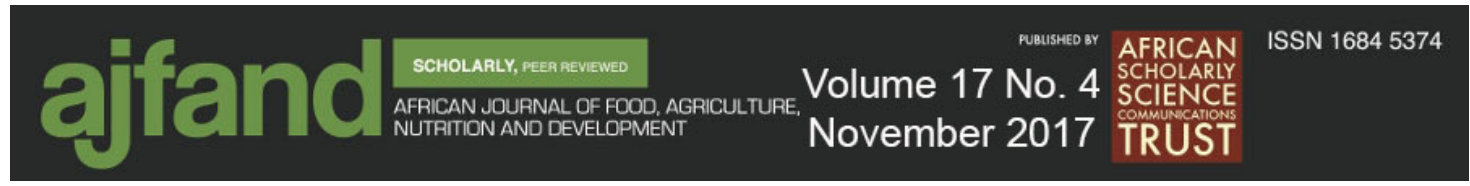

27. UNICEF. Nutrition Essentials: A Guide for Health Managers. Basics WHO/ UNICEF 1999.

28. Gebremedhin S Prevalence and differentials of overweight and obesity in preschool children in Sub-Saharan Africa. BJM 2015; 5 e009005. Doi: 10.1136/bmjopen-2015-009005.

29. O'Brien G and M Davies Nutrition Knowledge and Body Mass Index. Health Educ Res. 2007; Vol 22 (4): 571-575.

30. Zimbabwe National Statistics Agency. Zimbabwe Multiple Indicator Cluster Survey (2014): Key Findings Report. Harare, Zimbabwe: ZIMSTAT.

31. Jahns L and S Kranz High proportions of foods recommended for consumption by United States Dietary Guidances contain solid fats and added sugar: results from the National Health and Nutrition Examination Survey (2007-2008). Nutr J. 2014; $13: 23$.

32. Moreno MA, Furtner F and FP Rivara Breastfeeding as Obesity Prevention. Arch Pediatr Adolesc Med 2011; 165(8): 772doi10.1001/archpediatric2011.40.

33. Yan J, Liu L, Zhu Y, Huang G and PP Wang The association between breastfeeding and childhood obesity: a meta-analysis. BMC Public Health 2014; 14:1267.

34. Bundy D, Burbano C and M Grosh Rethinking School Feeding: Social Safety Nets, Child Development, and the education Sector. 2009; World Bank.

35. Buijsse B, Feskens EJM, Schulze MB, Forouhi NG, Wareham NJ, Sharp S, Palli D, Tognon G, Halkjaer J, Tionne A, Jakolisen MU, Overvad K, van der ADL, Du H, Sorensen TI and H Boeing Fruit and vegetable intakes and subsequent changes in body weight in European populations: results from the project on Diet, Obesity, and Genes (DiOGenes). The Am J Clin Nutri 2009; 90(1):202-209.

36. Ministry of Health. Zimbabwe Micronutrient Survey Report. Ministry of Health and Child Care 2015.

37. Oldewage-Theron WH, Dicks $\mathbf{E}$ and $\mathbf{M}$ Selepe Tea consumption patterns of 13-25 year olds in the Vaal Triangle, South Africa. A J F N S. 2002; Vol 2 (1):3845.

38. Gupta N, Goel K, Shah P, and MisraA. Childhood obesity in developing countries: Epidemiology, determinants and prevention. Endocr Rev 2012; Vol 33

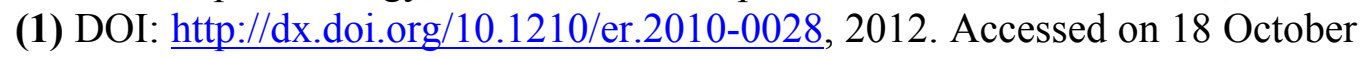
2013 


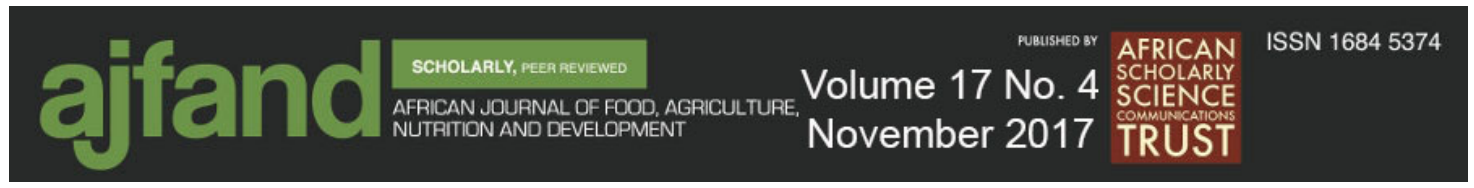

39. Liu J, Zhang A and $\mathbf{L} \mathbf{L i}$ Sleep duration and overweight/obesity in children: review and implications for pediatric nursing. J Spec Pediatr Nurs. 2012; 17/3:193-204 doi:10.1111/j.1744-6155.2012.00332.x.pmid:22734873.

40. Whitney E and S Rolfes Understanding Nutrition. 2008. Eleventh Edition. Thomson. Wadsworth. Australia. Canada. Mexico. Singapore. Spain. UK and USA.

41. Ministry of Health and Child Care, Zimbabwe IYCF Programme Review, 2012.

42. Etelson D, Brand DA, Patrick PA and A Shirali Childhood Obesity: Do Parents Recognize This Health Risk? Obes Res. 2003; 11:1362-1368. 